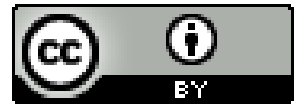

\title{
A CRIAÇÃO DA ESCOLA PÚBLICA PARA AS CLASSES DESFAVORECIDAS NO BRASIL E O DIREITO A EDUCAÇÃO E OBRIGATORIEDADE ESCOLAR: UMA VISÃO A PARTIR DO SÉCULO XIX
}

\author{
Maynara de Souza Melo \\ Universidade Federal do Acre, Mestrado em Educação, Programa de pós-Graduação \\ em Educação, Rio Branco, AC, Brasil.
}

Resumo: Este artigo tem como objetivo apresentar dados acerca da criação de escolas públicas Brasileira para crianças pobres e negras com uma visão a partir do império, período em que ocorre uma intensa discussão acerca da valorização da população das camadas tidas como inferiores. Para seu desenvolvimento, para tanto foi feita uma pesquisa bibliográfica em que foram utilizadas obras que compuseram a disciplina Educação Brasileira, do Mestrado em Educação da Universidade Federal do Acre ministrada pela Professora Doutora Elisabeth Miranda de Lima. Destaca-se aqui a necessidade da época em ensinar, civilizar e escolarizar a população da camada inferior além do relativo papel do Estado, dando enfoque nos avanços legais que foram importantes para a ascensão representativa do negro na educação.

Palavras-chave: história da educação; educação imperial; escola pública; desigualdade social.

\section{THE CREATION OF PUBLIC SCHOOLS FOR UNFAVORABLE CLASSES IN BRAZIL AND THE RIGHT TO EDUCATION AND SCHOOL OBLIGATION: A VIEW OF THE XIX CENTURY}

Abstract: This article aims to present data about the creation of Brazilian public schools for poor and black children with a view from the empire, a period in which there is an intense discussion about the valorization of the population of the lower classes. For its development, a bibliographic research was carried out, using works that comprised the discipline Brazilian Education, from the Master in Education at the Federal University of Acre taught by Professor Dr. Elisabeth Miranda de Lima. Here we highlight the need of the time to teach, civilize and educate the population of the lower tier in addition to the relative role of the State, focusing on the legal advances that were important for the representative rise of blacks in education.

\footnotetext{
${ }^{1}$ Licenciada em pedagógica pela Universidade Federal do Acre, aperfeiçoada em Ensino de História: Saberes e Fazeres de Matriz Africana e Indígena na Interamazônia pela Universidade Federal do Amapá, cursando Mestrado em Educação pelo Programa de Pós-Graduação em Educação. E-mail: maynaramelo3@gmail.com ; ORCID: https://orcid.org/0000-0003-3861-1512
} 
Keywords: history of education; imperial education; public school; social inequality.

\section{LA CREACIÓN DE LA ESCUELA PÚBLICA PARA CLASES DESVENTAJAS EN BRASIL Y EL DERECHO A LA EDUCACIÓN Y LA OBLIGACIÓN ESCOLAR: UNA VISIÓN DEL SIGLO XIX}

Resumen: Este artículo tiene como objetivo presentar datos sobre la creación de escuelas públicas brasileñas para niños pobres y negros con una mirada desde el imperio, un período en el que hay una intensa discusión sobre la valorización de la población de las clases bajas. Para su desarrollo se realizó una investigación bibliográfica, utilizando trabajos que comprendieron la disciplina Educación Brasileña, de la Maestría en Educación de la Universidad Federal de Acre impartida por la Profesora Dra. Elisabeth Miranda de Lima. Aquí destacamos la necesidad del tiempo de enseñar, civilizar y educar a la población del estrato inferior además del rol relativo del Estado, enfocándonos en los avances legales que fueron importantes para el ascenso representativo de los negros en la educación.

Keywords: historia de la educación; educación imperial; escuela pública; desigualdad social.

\section{LA CRÉATION D'ÉCOLES PUBLIQUES POUR LES CLASSES DÉFAVORABLES AU BRÉSIL ET LE DROIT À L'ÉDUCATION ET L'OBLIGATION SCOLAIRE: UNE VUE DU XIXe SIÈCLE}

Résumé: Cet article vise à présenter des données sur la création d'écoles publiques brésiliennes pour les enfants pauvres et noirs dans une perspective empire, une période où il y a une discussion intense sur la valorisation de la population des classes inférieures. Pour son développement, une recherche bibliographique a été menée, en utilisant des travaux qui comprenaient la discipline de l'éducation brésilienne, du Master en éducation de l'Université fédérale d'Acre enseigné par le professeur Dr. Elisabeth Miranda de Lima. Ici, nous soulignons la nécessité du temps d'enseigner, de civiliser et d'éduquer la population du niveau inférieur en plus du rôle relatif de l'État, en mettant l'accent sur les progrès juridiques qui ont été importants pour la montée représentative des Noirs dans l'éducation.

Mots-clés: histoire de l'éducation; éducation impériale; école publique; inégalité sociale.

\section{INTRODUÇÃO}

Este texto foi embasado na disciplina Educação Brasileira, do Mestrado em Educação da Universidade Federal do Acre ministrada pela Professora Doutora Elisabeth Miranda de Lima, o mesmo apresenta parte dos resultados de uma pesquisa de mestrado sobre como foi se construindo o processo de escolarização de negros e pobres desde a 
implementação da escola pública, relatando como a construção da escola tida como mecanismo de dominação colaborou para as desigualdades sociais e raciais hoje em dia.

Partindo do pressuposto de que os índices de evasão e repetência, em âmbito nacional, têm sido mais altos para as crianças do sexo masculino, em especial os meninos negros, a investigação procura compreender como se estabeleceu ao longo da história da educação brasileira, a relação do negro e pobre com a escola, além de averiguar acerca do processo de implementação da escola pública para essa classe tida como inferior.

A educação sendo uma das principais bases da sociedade, nela percebemos que ao longo da história da educação Brasileira, em especial da construção da escola pública, parte da população foi negligenciada com relação à educação, deste modo, de acordo com a Constituição de 1824 , por muitos anos a população de classe popular e a negra se manteve exclusa nas representatividades dentro da educação, assim negros e pobres não tiveram acesso à escola por longos períodos.

De acordo com Guimarães (2002), uma série de artigos escritos por afroamericanos entre 1910 e 1940, reafirma a crença generalizada num Brasil sem discriminações raciais, uma espécie de democracia racial onde a "raça" não definia o mérito individual. (NUNES, 2020, P. 696.)

Partindo desse pressuposto, a pesquisa tem como recorte temporal o período da monarquia século XIX. O artigo encontra-se organizado em dois itens, que trata sobre a criação da escola pública relatando sobre a inserção das crianças oriundas das classes "inferiores" na escola e o segundo relata sobre as crianças negras e mestiças e os obstáculos enfrentados por elas para adentrar a escola pública.

Após tais considerações acerca do processo de escolarização pública brasileira, evidencia-se que na época do império, século XIX a elite em sua maioria, não utilizava as escolas públicas, suas crianças tinham uma educação diferenciada, mais completa e intelectual. Porém, reflexões acerca das análises de Fonseca (2002) sobre a exclusão de negros da educação, sugerem que a escola pública era defendida pela elite como meio de civilizar e controlar as classes menos favorecidas, assim, a escola pública foi criada e destinada as classes tidas como inferiores, ou seja, crianças pobres e negras.

Destaca-se algumas questões de reflexão sobre instrução pública no Brasil do século XIX. A escola pública foi realmente criada para formar, ensinar e instruir as classes tidas como inferiores, ou veio apenas para moldar de acordo com os interesses da elite? O negro e o pobre receberam e recebem hoje uma educação que garanta um aprendizado 
de qualidade e uma possível ascensão social? Apesar da escola pública ter sido criada para as classes desfavorecidas, quais foram os limites de sua efetivação junto à população livre? Não se pretende com essas reflexões esgotar as análises dessas questões, objetivase contribuir com a discussão da origem da escola pública brasileira, pois somente a partir dessa pode-se compreender algumas características da escola pública na atualidade.

\section{A CRIAÇÃO DA ESCOLA PÚBLICA E A INSERÇÃO DAS CLASSES "INFERIORES" NA MESMA}

Segundo Souza (2000), os estudos sobre a instrução pública ampliam-se durante o século XIX, assim com o avanço da industrialização apela para uma mão de obra cada vez mais qualificada, deste modo surge a necessidade de qualificar mão de obra rápida e barata, criando-se assim as primeiras escolas públicas. O projeto de instrução pública é evidenciado no século XIX, este propunha o progresso material, intelectual e moral dos homens. Tal projeto foi analisado por Hippeau (1879) a fim de destacar a educação nacional.

Segundo Souza (2006), a educação das classes populares suscitou um amplo e prolongado debate sobre como organizar o sistema nacional de ensino, que tinha por objetivo organizar o ensino elementar de forma mais racionalizada e padronizada.

De acordo com Souza (2000), o projeto de instrução pública evidenciada no século XIX propunha o progresso material, intelectual e moral dos homens. A escola pública era tida como o não lugar do pobre e do negro, seu ambiente era frequentado por pessoas oriundas das classes média e alta, para ingressar na mesma, eram feitos exames de seleção, assim apenas aqueles que detinham de poder aquisitivo e intelectual ingressavam.

De acordo com a Constituição Imperial, no item 30 do artigo 179, cita a inviolabilidade dos direitos civis e políticos dos cidadãos brasileiros, entre outros dispositivos, a garantia da instrução primária gratuita a todos os cidadãos.

Legislando sobre a instrução publica, o principal cuidado da Assembléa Geral foi sua vulgarisação o quanto fosse possível: he deste modo, que se poderão nivelar pouco mais pouco menos as faculdades moraes dos Brazileiros, e que se aniquillara essa dependencia real, que as luzes de uma classe exerciam sob a cega ignorância da totalidade: dependencia esta que tanto contribuiu para a consolidação do Septro de ferro, que por trez seculos nos oprimio. (Carta aos 
Senhores Eleitores da Província de Minas Geraes, Revista do Arquivo Público Mineiro, 1904, p. 236 apud Cynthia Greive Veiga. Escola pública para os negros e os pobres no Brasil: uma invenção imperial).

A exclusão da classe popular e do negro se dava devido essa gestão do trabalho e da pobreza, em que a classe mais desfavorecida era inserida cada vez mais cedo no mercado de trabalho, outro fator era a nítida exclusão devido a cor da pele, em que negros não tinham os mesmos "privilégios" que os brancos.

Os estudos de Carlos Hasenbalg e Nelson do Valle e Silva,nos anos de1980/1990,são marcos nas discussões sobre desigualdades por cor/raça na população brasileira. Esses autores, de forma pioneira, utilizando-se das bases de dados nacionais (IBGE) disponíveis à época, no recorte cor/raça, indicaram que as desigualdades educacionais observadas entre brancos e negros não se limitavam exclusivamente a questões socioeconômicas (ARTES, OLIVEIRA, 2019, p. 40)

De acordo com o autor Luciano Mendes de Faria Filho (2002), com a criação a escola pública elementar destinada a todo e qualquer cidadão brasileiro, deu-se apenas a partir da Constituição Federal de 1824, no vigor da monarquia imperial, nesse momento ocorre uma intensa necessidade de instruir e civilizar o povo das camadas inferiores. A Constituição outorgada em 1824, durou todo o período imperial, em que dizia: "A instrução primária é gratuita para todos os cidadãos." Logo mais, a Legislatura de 1826 realizou vários debates sobre a educação popular, considerada premente pelos parlamentares.

Levando tais fatores em consideração, no dia 15 de outubro do ano de 1827, a Assembleia Legislativa aprovou a primeira lei acerca da educação pública nacional do Império do Brasil, estabelecendo que "em todas as cidades, vilas e lugares populosos haverá escolas de primeiras letras que forem necessárias"

Havia em várias províncias, uma intensa discussão acerca da necessidade de escolarização da população, sobretudo das chamadas "camadas inferiores da sociedade". Questões como a necessidade e a pertinência ou não da instrução dos negros (livres, libertos ou escravos), índios e mulheres eram amplamente debatidas e intensa foi a atividade legislativa das Assembleias Provinciais em busca do ordenamento legal da educação escolar. (FILHO, 2011, p. 135)

Reflexões feitas de acordo com o pensamento de Martins (2011), a criação das escolas de primeiras letras para negros e pobres, tidos como a camada inferior da 
sociedade, torna-se imprescindível, e a educação como mecanismo de controle da população deu-se dessa invenção imperial. Nesta época a classe popular e os negros aprendiam apenas o básico, a eles eram dados o ensino da leitura, da escrita, das contas, mas sem previsão para futuramente ter acesso ao ensino secundário, era apenas algo para inserir-se no mercado de trabalho, como mão de obra rápida e barata.

Essa forma de referir-se a escola que se queria generalizar para todo o povo, ou, conforme dizia-se em Minas Gerais, para as "classes inferiores da sociedade" que possibilita perceber, por um lado, que se queria generalizar os rudimentos do saber, ler, escrever, contar, não se imaginando por outo lado, uma relação muito estreita dessa escola com outros níveis de instrução: o secundário e o superior. Nessa perspectiva, pode-se afirmar, como muitos faziam a época, que, para a elite brasileira, a escola para pobres mesmo se tratando de brancos e livres, não deveria ultrapassar o aprendizado das primeiras letras. (FILHO, 2011, p. 135)

Naquela época apesar da população ser branca e livre, caso estivesse inserida na classe popular, era excluída de uma educação mais aprofundada, enquanto a elite cabia a tarefa da formação superior, do pensamento crítico, a classe popular era formada para ser classe trabalhadora. Reflexões acerca do pensamento de Enguita (1989) nos faz compreender que ocorria naquele momento o impedimento legal dos escravos em frequentar a escola públicas, esse fato ocorria em várias províncias do Império. Devido ao impedimento de negros escravos em frequentar a escola pública, outro fator que ocorreu, foi o impedimento de todo e qualquer negro, escravo ou não.

Ainda segundo Enguita (1989), apesar de impedidos de frequentar a escola pública, negros eram proletariados e o mínimo de instrução servira para que eles fossem utilizados como mão de obra, porém barata.

A população negra emancipada, que reunia a dupla condição de ser proletariado potencial e pertencer a uma raça considerada inferior, deu a alguns reformadores escolares a oportunidade de pôr em prática suas ideias sobre a roupagem da educação para uma sociedade livre e democrática. Arrancados a não muito tempo de uma economia de subsistência e nos faz apenas habituados, a maioria, ao trabalho mais regular das plantações de algodão ou as funções domésticas servis, emigravam em massa para o Norte industrializado e eram vistos como a base idônea - a mão de obra excepcionalmente barata - da necessária industrialização do Sul (ENGUITA, 1989, p. 123)

No império, se verifica a existência de escolas informais para negros, que muitas vezes ocorria de forma improvisada em fazendas, a educação para os negros vem a ser naquele momento como um método de manter o poder e dominação sobre eles. 
Se não se podia usar o chicote, devia-se recorrer a escola. Qualquer coisa antes de perder o controle da mão de obra negra por causa da emancipação, pois fazer o contrário seria desperdiçar alguns preciosos recursos. (ENGUITA, 1989: 123)

Logo a educação passa a ser essencial para controlar as classes inferiores, assim a escola pública vem a ser destinada a moldar o sujeito nos padrões sociais da época, como uma forma de domínio político que de acordo com o autor Jorge Nagle (1910 p. 137) “... a importância da escolarização, nesse contexto, é derivada das necessidades políticas, devido isso, outros argumentos, quaisquer que sejam, a escolarização ganha prestigio. ”

Os conteúdos que deveriam ser transmitidos aos alunos seriam o aprender a ler, a escrever, a fazer as quatro operações matemáticas, gramática da língua nacional e princípios de moral cristã e da doutrina da religião católica. Quanto ao método Lancaster, que deveria nortear a ação dos professores nessas escolas de primeiras letras, Saviani (2008, p. 128) explica:

Proposto e difundido pelos ingleses Andrew Bell, pastor da Igreja Anglicana, e Joseph Lancaster, da seita dos Quaquers, o método mútuo, também chamado de monitorial ou lancasteriano, baseava-se no aproveitamento dos alunos mais adiantados como auxiliares do professor no ensino de classes numerosas. Embora esses alunos tivessem papel central na efetivação desse método pedagógico, o foco não era posto na atividade do aluno. $\mathrm{Na}$ verdade, os alunos guindados à posição de monitores eram investidos da função docente. $\mathrm{O}$ método supunha regras predeterminadas, rigorosa disciplina e a distribuição hierarquizada dos alunos sentados em bancos dispostos num salão único e bem amplo. (SAVIANI, 2008, p.128).

Segundo Faria Filho (2000, p. 141-142), essa forma de ensino foi inviável no Brasil por dois motivos básicos:

Em primeiro lugar, porque não foram produzidas as condições materiais fundamentais para que tais escolas funcionassem; não havia espaços adequados, faltavam materiais didático-pedagógicos para os alunos. Em segundo lugar, alegava-se que os professores não eram formados para a realização do ensino segundo preconizava o método e que, além disso, a inexistência de instituições que 131 cuidassem da formação de tais professores era um grande limite à realização dos propósitos reformistas.

Para entendermos o contexto da educação brasileira, e como ela foi-se moldando a fim de atender a classe popular, faz-se necessário que compreendamos os diferentes tempos e espaços escolares no processo de institucionalização da escola primária no Brasil, que foram realizadas a partir de uma reflexão dos escritos de Almeida (1989). 
A escola como sendo um dos principais mecanismos de controle das classes inferiores, vem se moldando de acordo com o tempo, a inserção das classes desfavorecidas na mesma também se molda com o tempo. Surge assim ao longo da história os diferentes modelos educacionais descritos de acordo com Luciano Mendes de Faria Filho e Diana Gonçalves Vidal como:

- Escola de primeiras letras: visava um ensino doméstico, privado e público. Destinava-se aos ensinamentos de alfabetização e das primeiras formas de letramento.

- Escola elementar: Diz respeito a ensino com conhecimentos básicos e elementares para a formação das crianças e adolescentes como a escrita, o domínio das quatro operações, higiene, disciplina e consciência de sua realidade e status sociais.

- Escola primária: transmitia aos alunos os conhecimentos necessários para sua disciplina, dogmatização, aceitação, disposição, e condicionamento a sua realidade e status social. Aqui os ensinos secundários e superior estavam reservados apenas a elite.

- Sistema individualizado de ensino: Nesse modelo, o professor ministra alas apenas para um aluno, de modo particular, no seio familiar ou para demais integrantes da própria família.

- Sistema Simultâneo: Trata-se de um único professor lecionando suas aulas para uma turma com muitos alunos, mais ou menos uns 40 ou mais.

- Sistema Mútuo: O professor leciona suas disciplinas com a ajuda de alunos mais avançados em suas práticas de ensino.

- Método Intuitivo: Integralização do ensino e aprendizagem do aluno, através de processos internos e experiências extraescolares.

- Escolas no modelo fabril e industrial: Escolas tayloristas de adequação e adestramento aos alunos das classes "inferiores" como pobres e negros.

Apesar de todos os esforços em oferecer educação a toda a população, naquela época, havia um enorme problema que impedia o desenvolvimento do ensino no Brasil, al fator era a grande carência de professores devidamente preparados para o exercício do magistério. Consequência essa da não preparação desses profissionais durante todo o 
período colonial (1500 - 1822), visto que, naquele momento na visão das elites, não havia necessidade em expandir a escola de primeiras letras para as camadas populares.

Somente após a independência do Brasil, no ano de 1822, ocorre a necessidade de criar escolas voltadas para a formação de professores torna-se mais evidente, mas somente em 1835 foi criada a primeira escola normal na cidade de Niterói. Mas devido haver poucas escolas, e sendo a concentração da maioria da população na zona rural o ensino de primeiras letras ficava, a cargo da família. Reflexões acerca do pensamento de Faria Filho (2000), cita que, as famílias ricas contratavam professores para alfabetizar os seus filhos.

Ao adentrarmos nas décadas iniciais da Primeira República (1889 - 1930), a instituição era voltada para fins práticos e utilitários. Nesse momento é nítida a diferença entre a escola para os filhos da elite e a ausência de escola igualitária para os pobres. Quando se tinha essa escola, ela era como ensino profissionalizante para as famílias pobres, afim de que fossem meras mão de obra rápida, barata e qualificada ${ }^{2}$, isso tudo nada mais era do que um reflexo da exclusão vivenciada pelas classes tida como inferiores e da enorme desigualdade social que caracterizava a sociedade brasileira da época.

$\mathrm{O}$ ensino das primeiras letras no Brasil na época do Império era excludente, e voltado para formar a elite e funcionava de maneira muito precária comprometendo assim a qualidade de ensino. Sobre a precariedade das escolas, Saviani (2008, p. 130) ressalta que:

As críticas principais recaíam sobre a insuficiência quantitativa, falta de preparo (a tentativa de resolver esse problema com a criação de escolas normais ainda não surtira efeito e vinha sendo objeto de críticas constantes) parca remuneração e pouca dedicação dos professores; a ineficácia do método lancasteriano atribuída, sobretudo, à falta de instalações físicas adequadas à prática do ensino mútuo; e a ausência de fiscalização por parte das autoridades do ensino, o que tornava frequente nos relatórios a demanda pela implantação de um serviço de inspeção das escolas. A situação estava, pois, a reclamar uma ampla reforma da instrução pública.

Apesar da escola ser criada para as massas como controle das mesmas, os representantes da aristocracia rural, não estavam preocupados em expandir as escolas para os menos favorecidos, a mesma continuava sendo vista como algo para poucos, um instrumento de distinção social, constituindo assim uma das causas fundamentais para as

\footnotetext{
${ }^{2}$ Uma qualificação de atendesse os requisitos mínimos exigidos para adentar no mercado de trabalho precarizados, na maioria das vezes.
} 
estatísticas desanimadoras que o Brasil apresentava no campo da escolarização. Azevedo (1963, p. 574) relata os seguintes dados que dão uma dimensão do problema:

\begin{abstract}
A instrução primária, confiada às províncias e reduzida quase exclusivamente ao ensino de leitura, escrita e cálculo, sem nenhuma estrutura e sem caráter formativo, não colhia nas suas malhas senão a décima parte da população em idade escolar, e apresentava-se mal orientada não somente em relação às necessidades mais reais do povo, mas aos próprios interesses de unidade e coesão nacional. Em 1867, Liberato Barroso, apoiado em dados oficiais calculava em cerca de 107.500 (mais precisamente 107.483), o total da matrícula geral nas escolas primárias em todas as províncias para uma população livre de 8.830.000; nessa altura do Império, sobre cerca de 1.200.000 indivíduos em condições de recebê-la, apenas recebiam instrução, avaliando-se acima da estimativa, 120 mil, ou seja, a décima parte da população em idade escolar, ou ainda um indivíduo em 80 habitantes.
\end{abstract}

Naquele momento a preocupação dos governantes não era desenvolver um ensino que favorecesse as camadas mais pobres e sim criar faculdades para desenvolver o ensino superior, ocorrendo uma dualidade no ensino, sendo o ensino secundário e superior ofertado a elite com amparo do governo, e uma escola primária ou profissional precária, destinada a população de baixa renda, esse discurso impregna até a República no século $\mathrm{XX}$.

\title{
DIREITO A EDUCAÇÃO E A OBRIGATORIEDADE ESCOLAR DE 1924 A
}

\section{8}

Ao longo do século XIX, a escola acaba sendo transformada em um elemento central de homogeneização linguística e cultural. Reflexões acerca do pensamento de Martins (2011) nos traz à tona que nesse momento o Direito à Educação torna-se uma política pública, resultando assim a fusão do direito à educação com a obrigatoriedade escolar de tal modo que o poder constituído assumiu o compromisso não só de ofertá-lo, mas também se imbuiu juntamente com a sociedade civil da prerrogativa de torná-lo efetivo.

A partir da Constituição Imperial de 1824 ocorre o reconhecimento do direito à instrução primária gratuita, porém apenas aos que tivessem nascidos no Brasil e que fossem ingênuos, entretanto, a constituição não incluiu os escravos e índios. Como cita Horta: 
A Constituição Imperial de 1824 definiu, no Art. 179, n 32, a gratuidade da instrução primária para todos os cidadãos, como uma das formas de garantir a inviolabilidade dos direitos civis e políticos dos cidadãos brasileiros, fundados na liberdade, na segurança individual e na propriedade. (HORTA, 1998, p.11).

Fávero (2001) relata que a partir de 1827 é que a gratuidade passa a ser firmada na lei de 15 de outubro, em que determina a criação de escolas de primeiras letras em todas as cidades. Em 1830 o Brasil começa a consolidar o direito e obrigatoriedade escolar, já em 1832 havia apenas 180 escolas, sendo que destas 40 não possuíam professores. Somente em 1834, com o ato Adicional que vem a transferir para as províncias a obrigação de promover a instrução pública.

Com fim da monarquia no Brasil esperava-se que ocorresse grandes avanços no quesito educação, cidadania e nos direitos políticos e sociais, nesse momento a Constituição de 1891 dá aos estados a legislação e a oferta escolar. Ocorrendo assim uma separação entre ensino primário e o profissional, surgindo assim um ensino secundário fragmentado e com restrições ao Ensino Superior, não havendo assim obrigatoriedade de a família inserir as crianças na escola Azevedo (1976).

Nesse momento a gratuidade e a obrigatoriedade não foram garantidas ainda, tendo em vista que para obrigar os pais a matricularem seus filhos na escola, ela deveria ser gratuita. $\mathrm{O}$ analfabetismo na primeira república era algo em torno de $85 \%$ (Cury, 2008) e (Horta, 1998)

Somente a partir da constituição de 1934, ocorre de fato a obrigatoriedade do poder público em ofertar o ensino primário, de modo gratuito. Como cita Horta 1998: "Desta forma, direito a educação e obrigatoriedade escolar, embora não tenham surgido de forma concomitante no processo histórico, estão historicamente relacionados e devem ser estudados conjuntamente.” (HORTA, 1998, p. 10)

Deste modo podemos observar que diferente dos outros direitos sociais, o direito a educação está relacionado a obrigatoriedade escolar, como afirma o autor Huberman (s.d):

A educação considerada como um direito humano fundamental difere dos outros serviços que a sociedade tradicionalmente oferece a seus membros. O direito à educação não se reveste exatamente na mesma dimensão que, por exemplo, o direito a assistência médica gratuita, a alimentação mínima, a habitação decente ou ao socorro em caso de catástrofe natural. Estes são serviços que a sociedade aqueles que o solicitam. E geral, os cidadãos podem escolher entre utiliza-los ou 
prescindir deles e inclusive, adapta-los, via de regra, a seus interesses individuais. A educação, ao contrário, é via de regra obrigatória, e as crianças não se encontram em condições de negociaras formas segundo as quais a receberão. Paradoxalmente, encontramo-nos assim diante de um direito que é, ao mesmo tempo, uma obrigação. $\mathrm{O}$ direito é dispensado da educação, se esta fosse a preferência de uma criança ou de seus pais, não existe. (HUBERMAN, p. 58-9 apud HORTA, 1998, p.10)

Diferentemente dos outros direitos sociais, o direito à educação está estreitamente vinculado à obrigatoriedade escolar. Vale registrar a relação que se estabelece entre o direito à educação e a obrigatoriedade escolar, ou seja, a educação representa um direito e, ao mesmo tempo, uma obrigação!

No ano de 1835 é criada a lei n.13 de 28 de março, na província de Minas Gerais, que vem a multas os pais e/ou responsáveis de crianças que não frequentavam a escola, mas isso limitava-se apenas as livres. Com o regulamento de 17 de fevereiro de 1854 é que a instrução passa a ser obrigatória a todas as crianças.

O ano de 1874 é marcado pelo início da educação de jovens e adultos, que torna a instrução elementar obrigatória não apenas a crianças de sete a quatorze anos, mas sim a todos que possuíssem até dezoito anos e não tivessem recebido essa instrução. Já com o decreto de 19 de abril de 1879 o ensino passa a ser obrigatório a crianças de ambos os sexos, e geraria multas aos pais que não matriculassem as crianças na escola.

Com a Reforma Benjamin Constant, em 1890, a instrução primária passaria a ser: livre, gratuita e leiga, em que deveria ser aplicada em escolas primárias de $1^{\circ}$ grau assim como em escolas primárias de $2^{\circ}$ grau. Segundo Cury (1991) a gratuidade e a obrigatoriedade não se fizeram presentes na constituição de 1891, em que Cury cita:

Pode-se, nesse momento, interrogar o porquê da não-aprovação da gratuidade e obrigatoriedade. A primeira e mais expressa razão se encontra na ideia federativa. Postas a atribuições gerais de cada nível administrativo, ficaria a cargo das Assembleias Constituintes Estaduais a especificação mais detalhada destas competências (p.371) [...] O congresso, através das bancadas estaduais, tinha preocupação com os encargos já previstos e não queria auto-impor-se constitucionalmente mais um... A gratuidade e a obrigatoriedade seriam aceitas nos limites da organização federativa que abria espaços para as Constituintes estaduais legislarem sobre o assunto. Trata-se, aqui, de buscar na descentralização os caminhos da cidadania republicana. Aos estados federados competia, no âmbito de suas prerrogativas tributárias, mais do que "animar" as primeiras letras, efetiva-las (CURY, 1991, p.383). 
Assim, a obrigatoriedade escolar, tanto para os pais, em matricular seus filhos, quanto ao estado em ofertar, ainda era debilitada e geraria doravante muitos debates, não encontrando assim espaço no que se refere a legislação federal que antecede o ano de 1930.

Na constituição de 1934, aparece finalmente a obrigação do poder público em ofertar o ensino primário, gratuito e obrigatório nas escolas oficiais. De acordo com o Manifesto dos Pioneiros proclama em 1932 que:

A laicidade, gratuidade, obrigatoriedade e coeducação são outros tantos princípios em que assenta a escola unificada e que decorrem tanto da subordinação a finalidade biológica da educação de todos os fins particulares e parciais (de classes, grupos ou crenças), como do conhecimento do direito biológico que cada ser humano tem a educação. [...] A gratuidade extensiva a todas as instituições oficiais de educação é um princípio igualitário que torna a educação, em qualquer dos seus graus, acessível não a uma minoria, por um privilégio econômico, mas a todos os cidadãos que tenham vontade e entejam em condições de recebe-la. Aliás, o Estado não pode tornar o ensino obrigatório, sem torna-lo gratuito. A obrigatoriedade que, por falta de escolas, ainda não passou do papel, nem em relação ao ensino primário, e se deve estender progressivamente até uma idade conciliável com o trabalho produtor, isto é, até aos 18 anos, é mais necessária ainda "na sociedade moderna em que o industrialismo e o desejo de exploração humana sacrificam e violam a criança e o jovem", cuja educação é frequentemente impedida ou mutilada pela ignorância dos pais ou responsáveis e pelas contingências econômicas. (MANIFESTO DOS PIONEIROS, 1932, p. 48-9 apud HORTA, 1998.)

Com o passar dos anos, a Constituição de 1946 reafirmou o direito à educação, a obrigatoriedade e gratuidade do ensino primário. Em 1948 ocorre a promulgação da Lei Orgânica que diz: “o ensino primário elementar (4 anos) é obrigatório de sete a doze anos. Pais ou responsáveis que descumprirem estarão sujeitos ás penas - detenção de quinze dias a um mês ou multa.

A questão da obrigatoriedade escolar é discutida quando da votação da emenda apresentada por Gustavo Capanema. Na sessão de 31/8/46, ao se debater a respeito da obrigatoriedade do ensino técnico profissional e agrícola, quando pereira de Souza pergunta se esta obrigatoriedade significa que "todos os Estados e a União devem ter obrigatoriamente seu sistema educativo [...] ou se é obrigatório que todo brasileiro frequente escola", Capanema esclarece que, na legislação "quando se diz obrigatoriedade, tem de entender-se que ela é para o aluno" (Brasil, 1946. v.XXIII, p.384). Assim, para Capanema, o conceito de obrigatoriedade escolar, tal como se apresentava na legislação, não implicava dever do Estado perante o indivíduo, mas somente dever do indivíduo perante o Estado. E será essa concepção restrita de obrigatoriedade escolar que se fará presente na carta Constitucional de 1946 (Horta, 1998. P. 20) 
Chegamos então à criação da LDB - Lei de Diretrizes e bases promulgada em 1961 que incorporará o direito à educação primária, porém a obrigatoriedade em matricular a criança era ignorada em alguns casos, principalmente se houvesse poucas escolas, matrículas encerradas ou, ainda, em município sem recursos. Como cita nos seguintes termos:

Art. $2^{\circ}$ - A educação é direito de todos e será dada no lar e na escola.

Art. $3^{\circ}$ - O direito a educação é assegurado: pela obrigação do poder público e pela liberdade de iniciativas particular de ministrarem o ensino em todos os graus, na forma da lei em vigor;

Art. $27^{\circ}-\mathrm{O}$ ensino primário é obrigatório a partir dos sete anos, e só será ministrado na língua nacional. Para os que o iniciarem depois dessa idade poderão ser formadas classes especiais ou cursos supletivos correspondentes ao seu nível de desenvolvimento.

Art. $30^{\circ}$ - Não poderá exercer função pública, nem ocupar emprego em sociedade de economia mista ou empresa concessionária de serviço público, o pai de família ou responsável por criança em idade escolar sem fazer prova de matricula desta, em estabelecimento de ensino, ou de que lhe está sendo ministrada educação no lar.

Parágrafo Único - Constituem casos de isenção, além de outros previstos em lei: a) comprovado estado de pobreza do pai ou responsável; b) insuficiência de escolas; c) matricula encerrada; d) doença ou anomalia grave da criança. (HORTA, 1998. p. 21).

Em 1964 o debate educacional logo após o período da ditadura militar, ocorre várias tentativas neoliberais em acabar com alguns direitos conquistados nas políticas sociais e na educação. Nesse momento revoga-se a vinculação no âmbito da união, o que se reitera na emenda de 1969, sendo que os municípios não ficam isentos dela obrigandose descontar $20 \%$ dos seus impostos para o ensino primário de suas redes. Em 1983, emenda Calmon, por meio da lei no $7348 / 85$ resgata a vinculação.

Por fim, ao analisar a obrigatoriedade escolar e o direito a educação a partir da constituição de 1998, percebe-se que o direito a educação e obrigatoriedade do ensino é estabelecida de fato. Em que em seu artigo 208, relata sobre os princípios da educação como um direito público:

Art. 208 - O dever do Estado com a educação será efetivado mediante a garantia de:

I Ensino fundamental, obrigatório e gratuito, inclusive para os que a ele não tiveram acesso na idade própria;

II Progressiva extensão da obrigatoriedade e gratuidade ao ensino médio; $\S 1^{\circ}-\mathrm{O}$ acesso ao ensino obrigatório pelo poder público subjetivo. 
$\S \quad 2^{\circ}$ - O não-oferecimento do ensino obrigatório pelo poder público, ou sua oferta irregular, importa responsabilidade da autoridade competente.

Assim, podemos observar que o direito à educação e a obrigatoriedade do ensino, foi tema de muitos debates, mas que a constituição federal vem normas para fechar esse círculo de discussões e disputas. De acordo com Cury (2008) "Em primeiro lugar, o direito à Educação é tomado como um direito de todos", o autor explica que nas Constituições anteriores à ditadura, havia a defesa do direito de todos à escolaridade, mas a gratuidade era restrita àqueles que comprovassem carência de recursos.

Hoje a educação é para todos, como um direito inviolável, gratuito e obrigatório a todas as pessoas, direito esse sem distinção de raça, classe, ou qualquer outro marcador social, objetivando não somente garantir uma formação mínima para os sujeitos, mas possibilitando aos mais altos níveis de escolaridade se assim os sujeitos quiserem.

\section{CONSIDERAÇÕES FINAIS}

A partir das reflexões apresentadas nesse artigo, pode-se observar que o objetivo da escola idealizada para o povo nos princípios de igualdade não foi alcançado, o ensino não proporcionou os princípios propostos de igualdade, obrigatoriedade e gratuidade. $\mathrm{O}$ direito à educação e a obrigatoriedade do ensino foi tema de muitos debates e lutas, todas as conquistas legais nesse campo, são frutos de diversas mobilizações, que só ganham valor e destaque a partir no momento em que se torna de fato lei na constituição de 1988 e o poder público passa a se mobiliza para cumprir a efetivação do mesmo.

\section{REFERÊNCIAS BILIOGRÁFICAS}

ALMEIDA, José Ricardo Pires de. História da instrução pública no Brasil (1500-1889). História e legislação. São Paulo: EDUC; Brasília: INEP/MEC, 1989.

CURY, C.R.J. A educação básica como direito. Cadernos de Pesquisa, São Paulo, v.38, n.134, mai./ago.2008.

CURY, C.R.J. Sistema Nacional de Educação: desafios para uma educação igualitária e federativa. Educação e Sociedade, Campinas, vol.29, n.105, set./dez. 2008.

ENGUITA, Mariano Fernandes. A Face Oculta da Escola: educação e trabalho no capitalismo. Porto Alegre: Artes Medina. 1989. 
FARIA FILHO, L. M. Instrução elementar no século XIX. In: LOPES, E. M. T.; FARIA. 2011.

FÁVERO, O A educação nas constituintes brasileiras 1823-1988 Campinas: Autores associados, 2001.

FONSECA, M.V. A educação dos negros: uma nova face do processo de abolição da escravidão no Brasil. Bragança Paulista: ESUSF, 2002.

FILHO, L. M.; VEIGA, C. G. (Orgs.). 500 anos de educação no Brasil. 2. ed. Belo Horizonte: Autêntica, 2000. p. 135-150.

HORTA, J S B. Direito a educação e obrigatoriedade escolar. Cadernos de Pesquisa, São Paulo, n. 104, p.5-34, jul. 1998.

MARTINS, Leda Maria. 500 anos de educação no Brasil. 5ed . Belo Horizonte: Autentica: 2011.

NAGLE, Jorge. Educação e sociedade na primeira república. 2ed. Rio de Janeiro. 2001

SOUZA, Rosa Fátima. Inovação educacional no século XIX: A construção do currículo da escola primária no Brasil. Cadernos Cedes, ano XX, n 51, novembro/2000.

Recebido em: 22/12/2020

Aceito em: 01/11/2021 